\title{
Pneumocephalus Associated with Aggressive Pneumococcal Meningitis
}

\author{
Isabel Taveira ${ }^{1}$, Hipólito Nzwalo ${ }^{1,2}$, José Sousa e Costa ${ }^{1}$, Pedro Moreira ${ }^{3}$ \\ ${ }^{1}$ Internal Medicine Department, Litoral Alentejano Hospital, Monte do Gilbardinho, Santiago do Cacém, Portugal \\ ${ }^{2}$ Faculty of Medicine and Biomedical Sciences, University of Algarve, Faro, Portugal \\ ${ }^{3}$ Intensive Care Unit, Litoral Alentejano Hospital, Monte do Gilbardinho, Santiago do Cacém, Portugal
}

Received: $19 / 04 / 2020$

Accepted: $20 / 04 / 2020$

Published: $28 / 04 / 2020$

How to cite this article: Taveira I, Nzwalo H, Sousa e Costa J, Moreira P. Pneumocephalus associated with aggressive pneumococcal meningitis. EJCRIM 2020;7: doi:10.12890/2020_001677.

Conflicts of Interests: The Authors declare that there are no competing interests.

This article is licensed under a Commons Attribution Non-Commercial 4.0 License

\section{ABSTRACT}

A 44-year-old woman presented with headache and delirium. Brain tomography indicated pneumocephalus, while blood and cerebrospinal fluid cultures revealed Streptococcus pneumoniae. Despite antibiotic treatment and admission to the intensive care unit, the patient died 3 days later. Pneumocephalus in association with meningitis is very rare and may be caused by gas produced by microorganisms.

\section{LEARNING POINTS}

- Non-traumatic pneumocephalus should raise the suspicion of meningitis and prompt suitable treatment.

- Previous pneumococcal saccharide conjugate vaccine administration does not exclude the possibility of serious pneumococcal infection.

\section{KEYWORDS}

Pneumocephalus, meningitis, pneumococcal

\section{CASE DESCRIPTION}

A 44-year-old woman was admitted in the emergency department after 3 days of headache followed by hyperactive delirium. Brain tomography showed a hypodense lesion on the superior left cerebellum compatible with pneumocephalus (Fig. 1a).

A lumbar puncture was performed for extensive microbiological investigation and broad-spectrum antibiotics were initiated with vancomycin, ceftriaxone and ampicillin. Cerebrospinal fluid analysis showed 42/ $\mathrm{mm}^{3}$ leucocytes with polymorphonuclear leukocytes and clear glucose consumption ( $1 \mathrm{mg} / \mathrm{dl})$. The blood cultures as well as the cerebrospinal fluid culture disclosed the presence of Streptococcus pneumoniae (against which the patient had been vaccinated 3 years previously with the pneumococcal saccharide conjugate vaccine). Antimicrobial therapy was adjusted accordingly. Follow-up brain imaging ( $48 \mathrm{~h}$ later) showed resolution of the pneumocephalus (Fig. $1 \mathrm{~b}$ ). Despite receiving full intensive care treatment, the patient deteriorated and died on the third day after admission.

\section{DISCUSSION}

Pneumocephalus is defined as the presence of air in the intracranial cavity. It is usually caused by head trauma, surgery, central nervous system tumours and diagnostic/therapeutic procedures ${ }^{[1]}$. This occurrence in association with meningitis is extremely rare ${ }^{[2]}$.

Spontaneous, non-traumatic pneumocephalus should always raise the suspicion of meningitis and prompt suitable treatment ${ }^{[3]}$. In situ production of gas by microorganisms is the most likely explanation for meningitis-associated pneumocephalus ${ }^{[3,4]}$. 

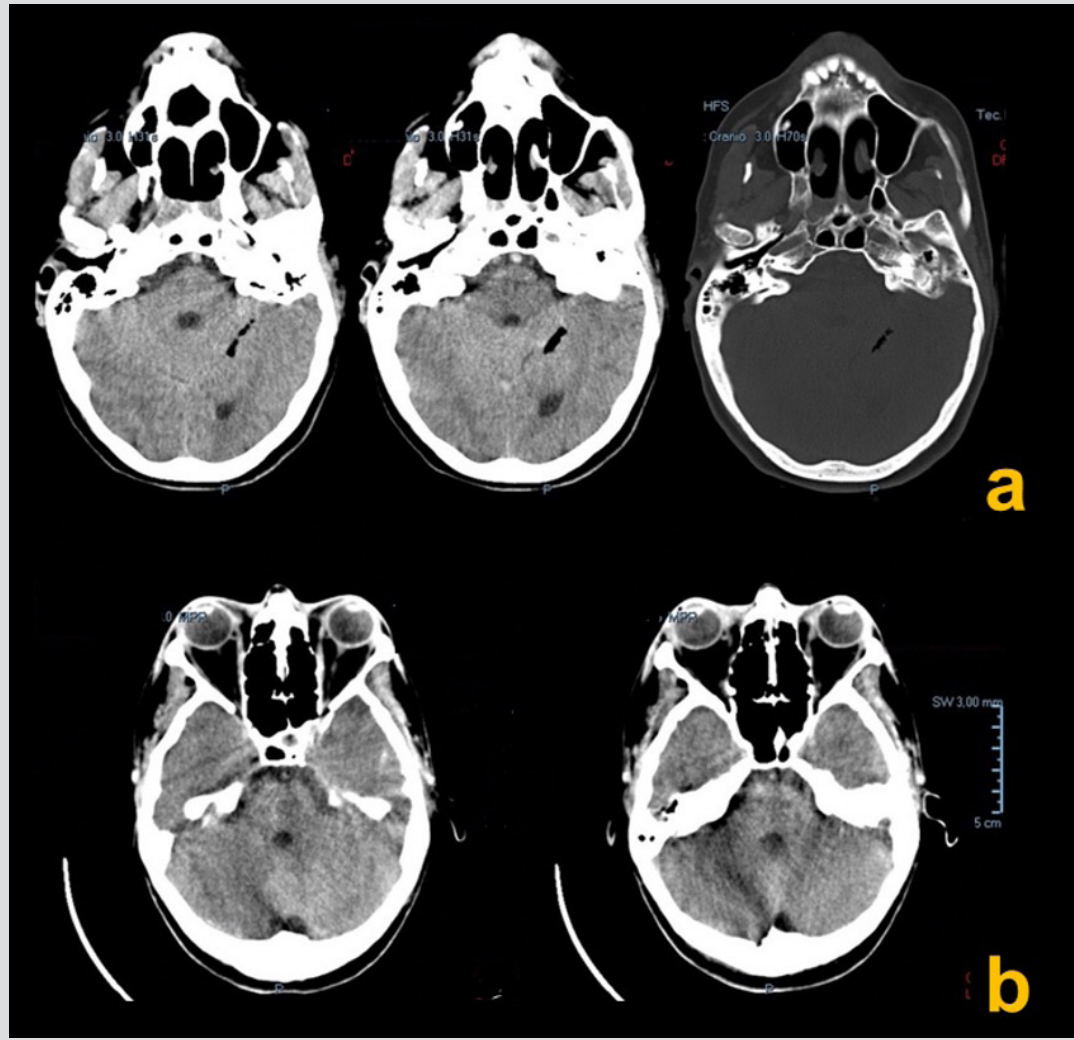

Figure 1. (a) CT scan showing pneumocephalus on the superior left cerebellum; (b) second CT scan (48 $\mathrm{h}$ later) with disappearance of the pneumocephalus

\section{REFERENCES}

1. Jayaram S, Jadhav S, Rathod D, Tarvade S, Soman A. Meningitis: an unusual cause of pneumocephalus. J Assoc Physicians India 2004;52:67-68.

2. Pantangi P. Cherian SV. Pneumocephalus: a rare presentation of streptococcal meningitis. Intern Med 2011:50:2249-2250.

3. Rota E, Sacchini D, Paolillo F, Morelli N, Immovilli P, lafelice I, et al. Pneumocephalus as uncommon presentation of pneumococcal meningitis. Neurol India 2013;61(3):314-315.

4. Penrose-Stevens A, Ibrahim A, Redfern RM. Localized pneumocephalus caused by Clostridium perfringens meningitis. Br J Neurosurg 1999;13:85-86. 